\title{
Age-dependent release of high-mobility group box protein-1 (HMGB1) and cellular neuroinflammation after traumatic brain injury in mice
}

Kyria M. Webster $\mathrm{MSc}^{1}$, Ms. Mujun Sun $\mathrm{MSc}^{1}$, A.Prof. Peter J. Crack $\mathrm{PhD}^{2}$, Prof. Terence J. O'Brien $\mathrm{MD} \mathrm{PhD}^{1,3}$, A/Prof. Sandy R. Shultz $\mathrm{PhD}^{1,3}$, Dr. Bridgette D. Semple $\mathrm{PhD}^{1,3}$

(1) Department of Medicine (Royal Melbourne Hospital), The University of Melbourne, Royal Parade, Parkville, VIC, Australia

(2) Department of Pharmacology and Therapeutics, The University of Melbourne, Royal Parade, Parkville, VIC, Australia

(3) Department of Neuroscience, Monash University, Commercial Road, Melbourne, VIC, Australia

Running title: Age impacts inflammation after TBI

\section{*Corresponding author:}

Bridgette D. Semple, Ph.D.

Department of Neuroscience

Central Clinical School, Monash University

The Alfred Centre

99 Commercial Road

Melbourne VIC 3004

Australia

This is the author manuscript accepted for publication and has undergone full peer review but has not been through the copyediting, typesetting, pagination and proofreading process, which may lead to differences between this version and the Version of Record. Please cite this article as doi: 10.1002/cne.24589

This article is protected by copyright. All rights reserved. 


\title{
Bridgette.Semple@monash.edu
}

Phone: +61 399030893

Fax: +61399030556

Acknowledgements: This work was supported by project and fellowship funding to BDS and SRS from the National Health and Medical Research Council of Australia (NHMRC), the Rebecca L Cooper Medical Research Foundation, and the University of Melbourne. KMW and MS were supported by Australian Government Research Training Program (RTP) Scholarships. No competing financial interests exist.

\begin{abstract}
:
Accumulating research suggests that children may be more vulnerable to poor long-term outcomes after traumatic brain injury (TBI) compared to adults. The neuroinflammatory response, known to contribute to neuropathology after TBI, appears to differ depending upon age-at-insult, though this response has not been well-characterized. Elevated levels of a key initiator of inflammation, high mobility group box protein 1 (HMGB1), have been associated with worsened outcomes after TBI in young patients. This study therefore aimed to characterize the acute time course of key mediators of the inflammatory cascade, including HMGB1, after pediatric and adult TBI. Male C57Bl/6 mice were subjected to severe controlled cortical impact or a sham control surgery, at either early adulthood (810 weeks) or a pediatric age (3 weeks). Cortical tissue was collected for Western blot detection of astrocyte and microglial activation (GFAP and CD68) and HMGB1 at 2 h, 6 h, 24 h, 3 d and 7 d postinjury, and serum was collected for enzyme-linked immunoassays to quantify peripheral HMGB1. An additional cohort of brains were harvested at $3 \mathrm{~d}$ post-injury for immunofluorescence staining. Results demonstrated a temporal profile of CD68, GFAP and HMGB1 after TBI relative to sham, which differed between the adult and pediatric cohorts. An increase in peripheral HMGB1 was found in
\end{abstract}


serum from pediatric TBI mice, which was not evident in adult serum. Together, these findings demonstrate that HMGB1 and the downstream cellular inflammatory response is influenced by ageat-insult, which may be an important consideration for treatment strategies aiming to ameliorate this response after TBI.

Keywords: inflammation, high mobility group box protein 1, pediatric, traumatic brain injury, age, RRID:AB_444360, RRID:AB_10013382, RRID:AB_1141557, RRID:AB_783595, RRID:AB_2305186, RRID:AB_10679369, RRID:AB_2617143, RRID:AB_2298772, RRID:AB_2224402, RRID:AB_11212597, RRID:AB_141637, RRID:AB_2534105, RRID:AB_141607. 


\section{Introduction}

Traumatic brain injury (TBI) is a leading cause of morbidity and mortality, particularly in children under the age of 5 who represent the highest incidence of Emergency Department admissions for TBI compared to all other age groups (Thurman, 2016). Both experimental (Bittigau et al., 2004) and clinical data (Adelson et al., 1997; Koskiniemi et al., 1995; Mazzola \& Adelson, 2002) has suggested that the developmental age-of-insult can significantly influence the manifestation, prognosis and outcomes after TBI. Specifically, studies have suggested that poorer outcomes are strongly associated with younger age-at-insult, particularly after severe TBI (Anderson et al., 2005; Ferriero \& Miller, 2010; Giza et al., 2007; Levi et al., 1991; Prins et al., 1996). Children who suffer a TBI under the age of 4 show the most pronounced cognitive and psychosocial deficits in later life (Anderson et al., 2005; Durkin et al., 1998; Ferriero \& Miller, 2010; Selassie et al., 2008). These deficits may be delayed in presentation, emerging alongside brain maturation up to at least 16 years post-injury (Ewing-Cobbs et al., 2004; Keenan \& Bratton, 2006; Ryan et al., 2014; Ryan et al., 2015).

Various secondary injury processes after TBI, including the neuroinflammatory response, may contribute to the emergence of cognitive and psychosocial deficits (Cederberg \& Siesjo, 2010; Stevenson et al., 2000). Age-dependent vulnerability of the developing brain to secondary injury has been known for some time, with the immature brain being more susceptible (Bittigau et al., 2004). Experimental studies have also shown that neuroinflammation in response to an insult can vary in magnitude and composition as a consequence to developmental age, with several studies reporting an enhanced propensity for heightened inflammation during early postnatal life, described as a 'window of susceptibility’ (Galea et al., 2007; Schoderboeck et al., 2009; Umehara et al., 1990). One of the earliest studies to investigate this found that 3-week old rats had a higher susceptibility to interleukin (IL)-1 $\beta$-induced blood brain barrier (BBB) breakdown compared to adults, in a model of intracerebral 
cytokine injection (Anthony et al., 1998; Anthony et al., 1997). This differential response may be attributed to the unique global expression profile of chemokines in the younger brain that is reportedly distinct from that in the adult CNS (Schoderboeck et al., 2009). Several other studies have since explored the age-specific responses of major cell types involved in neuroinflammation, in both physiological and pathological scenarios. The infiltration of polymorphonuclear leukocytes into brain parenchyma is an early hallmark of inflammation after TBI (Asensio \& Campbell, 1999; MorgantiKossmann et al., 2002). The level of circulating neutrophils is reportedly much higher in young postnatal day 7 (p7) rats compared to adult animals (Lawson \& Perry, 1995), which may account for the prolonged and exacerbated infiltration of neutrophils observed after experimental TBI in 3 week old mice as compared to adult mice (Claus et al., 2010). In contrast, a lessened microglial activation was observed in the neonatal compared to the adult brain in another experimental model, persisting for up to 4 days and concurrent with vascular damage (Lawson \& Perry, 1995).

Most previous studies examining the inflammatory response in the developing brain have focused on other diseases with common pathological pathways to TBI, such as stroke or ischemic brain injury. For example, in an experimental model of multiple sclerosis, chemokines involved in recruiting monocytes and $\mathrm{T}$ cells to a lesion area in the brain, including CC chemokine ligand 2 (CCL2), CCL3, and CCL6, were upregulated by 2-6 fold increase in the juvenile brain compared to adults (ABS, 2004; Elhofy et al., 2005; Karpus et al., 1995; Luo et al., 2000). However, in the context of TBI, comparison between the adult and pediatric brain responses in the acute stages after injury have been poorly described. Clinically, limited evidence to date also suggests age-dependent differences in how the immune system responds to TBI. For example, production of IL-1 and IL-10 from peripheral monocytes is increased in newborns in response to pathogenic insult compared to adults (Levy, 2007). In addition, several inflammatory cytokines are robustly upregulated in both CSF and serum of 
children presenting with TBI, including IL-1 $\alpha$, IL-16, IL-12 and TNF- $\alpha$ (Berger et al., 2009; Buttram et al., 2007; Whalen et al., 2000). However, a direct comparison across different neurodevelopmental states and how they respond to injury has not yet been conducted.

One inflammatory mediator that is generating interest for both adult and pediatric brain is high mobility group box protein 1 (HMGB1) (Gao et al., 2012; Kim et al., 2006). HMGB1 is an essential chromatin binding protein found in the nucleus of most cells, involved in the formation of nucleosomes and the regulation of gene transcription (Gerlitz et al., 2009; Stros, 2010; Venters \& Pugh, 2009). However, when released into the extracellular space, HMGB1 acts as a damage associated molecular pattern to recruit a potent inflammatory response and recruit various inflammatory mediators, as well as contributing to apoptosis and cell loss (Bianchi \& Manfredi, 2007; Harris et al., 2012). Once in the extracellular milieu, HMGB1 can interact with many different cellsurface receptors, including the receptor for advanced glycation end products (RAGE), Toll-like receptor (TLR) 2, 4 and 9, and macrophages antigen-1 (Bianchi \& Manfredi, 2007; Harris et al., 2012; Tian et al., 2007; Venereau et al., 2012; Venereau et al., 2013; Yang et al., 2013). Due to this receptor promiscuity, HMGB1 can trigger a wide range of innate immune responses, including fever, leukocyte chemotaxis, and BBB dysfunction (Harris et al., 2012; Yang et al., 2013). An increasing number of studies have implicated HMGB1 as an upstream mediator of the inflammatory cascade after experimental brain injury in adult rodents (Gao et al., 2012; Okuma et al., 2012). However, HMGB1 may be of particular importance to the injured pediatric brain, as it displays age-dependent variations in expression under basal conditions. In rodents, the highest basal protein expression of HMGB1 in all brain regions is at 2 weeks of age, corresponding to infancy in humans (Enokido et al., 2008). Clinically, one study has examined HMGB1 levels after TBI in young patients up to 16 years of age, and found that higher levels of HMGB1 in CSF were associated with poorer 
Glasgow Outcome Scores, an indicator of less favorable outcomes, at 6 months post-injury (Au et al., 2012).

Understanding the time course of expression and release of HMGB1 in the pediatric injured brain, in the context of the cellular neuroinflammatory response, may reveal important similarities or differences relative to how the adult brain responds to TBI, with important clinical implications. The current study therefore aimed to delineate the temporal profiles of key cellular neuroinflammatory markers, alongside HMGB1 levels, in the pediatric and adult brain, after experimental TBI using a well-characterized mouse model.

\section{Methods}

\section{2. $1 \quad$ Mice}

Male C57Bl/6 mice (Mus musculus) were obtained from the on-site breeding colony at the Florey Institute of Neuroscience and Mental Health animal facility in Melbourne, generated from breeding pairs purchased from the Animal Resource Centre (Perth, Australia). 68 mice were aged 8-9 weeks and 67 mice were aged 3 weeks [postnatal day 21 or 22 (p21-22)] at the time of brain injury. All mice were group housed in specific pathogen free conditions under a $12 \mathrm{~h}$ light/dark cycle, with access to food and water ad libitum for the duration of the experiment. All experimental procedures were approved by the University of Melbourne Animal Ethics Committee (\#15-016-UM) and conducted in accordance with the guidelines of the Australian Code of Practice for the Care and Use of Animals for Scientific Purposes.

\section{2 Experimental groups}

This article is protected by copyright. All rights reserved. 
For each age group, mice were randomly assigned to receive either a sham-operation or controlled cortical impact (CCI) TBI injury. After TBI, mice were randomly assigned to terminal time points of 2 h, 6 h, 24 h, 3 d and $7 \mathrm{~d}$ (n=7-8/group for protein analysis) for tissue collection. An additional cohort were collected at $3 \mathrm{~d}$ (n=6/group) for immunofluorescence staining (Table 1). Age-matched naïve mice were also analyzed to determine if there was any difference with sham mice in any of the quantitative methods. All analyses were conducted by investigators blinded to group allocation (age/injury status).

\section{3 CCI model}

CCI was performed as previously described (Tong et al., 2002). Mice were positioned in a stereotaxic frame for all surgical procedures and administered subcutaneous (s.c.) $0.05 \mathrm{mg} / \mathrm{kg}$ buprenorphine for analgesia. Under isoflurane anesthesia, the skull was exposed by midline incision and a $4 \mathrm{~mm}$ diameter circular craniotomy located laterally over the parietal lobe, midway between Bregma and Lambda, was performed using a micro-drill to expose the intact dura of the brain. The injury was generated using a $3.0 \mathrm{~mm}$ convex tip, with a velocity of $4.5 \mathrm{~m} / \mathrm{s}$, penetration depth of $1.5 \mathrm{~mm}$ for a sustained depression of 150 ms. Following impact, the scalp was closed with sutures and each animal was administered $0.5 \mathrm{ml}$ isotonic saline s.c. to prevent dehydration. Sham mice underwent all surgical procedures except for the cortical impact. Following surgery, mice were individually housed in heat chambers and allowed to recover for 30-60 min before returning to group housing, with weights monitored daily until euthanasia. As the demographic comprising the pediatric population can be wide-ranging in age, we here defined pediatric as 3 weeks of age in mice, to developmentally represent a toddler-aged child (Semple et al., 2013). This age group are known to show particular vulnerability both to the occurrence of TBI, as well as poor functional outcomes as a consequence (Keenan \& Bratton, 2006; Kieslich et al., 2001). The same injury parameters were used for both 
pediatric and adult cohorts, as previous studies have demonstrated comparable brain volumes between animals at these two ages (3 weeks and 8-9 weeks), despite differences in body weight (Claus et al., 2010; Prins \& Hovda, 2003). Time from when the animal was removed from anesthesia to when they recovered their righting reflex was obtained as an acute indicator of injury.

\section{4 Tissue collection}

Animals were culled at the various time points ( 2 h, 6 h, 24 h, $3 \mathrm{~d}$ and $7 \mathrm{~d}$ ) by intraperitoneal injection of $100 \mathrm{mg} / \mathrm{kg}$ sodium pentobarbitone. Blood was collected by cardiac puncture, then brains were extracted and divided into ipsilateral and contralateral parietal neocortex and hippocampal samples.

Tissue was snap frozen and stored at $-80^{\circ} \mathrm{C}$ until use. Additional mice were euthanized by transcardial perfusion-fixation at $3 \mathrm{~d}$ post-injury, and brains were embedded in paraffin before sectioning to $7 \mu \mathrm{m}$ thick coronal sections (Table 1).

\section{5 Antibody Characterization}

Several primary and secondary antibodies were used for Western blot (WB) and immunofluorescence staining, as described in subsequent sections. Antibodies were as follows:

- Rabbit polyclonal anti-HMGB1 (Abcam \#ab18256; RRID:AB_444360). Reacts with mouse, rat and human; developed against a synthetic peptide within Human HMGB1 aa 150 to the Cterminus (internal sequence) conjugated to keyhole limpet haemocyanin. The exact sequence is proprietary. Detects a band of $~ 30 \mathrm{kDa}$ by WB; knockout-based validation.

- Rabbit polyclonal anti-GFAP (Dako, \#Z0334, RRID: AB_10013382), purified immunoglobulin fraction of rabbit antiserum. Reacts with GFAP in many species including human, mouse, rat, sheep, cat, and dog. Developed against GFAP peptide isolated from bovine spinal cord. Detects a band of $\sim 50 \mathrm{kDa}$ by WB.

This article is protected by copyright. All rights reserved. 
- Mouse monoclonal anti-CD68 (Abcam, \#ab31630, RRID:AB_1141557), purified protein A, IgG1. Raised against a single chain glycoprotein of $110 \mathrm{kDa}$ expressed predominantly on the lysosomal membrane of myeloid cells. Reacts with mouse, rat and human.

- Goat polyclonal anti-GAPDH (Abcam, \#sc-48166, RRID:AB_783595), IgG (I-19). Raised against an epitope mapping within an internal region of GAPDH of human origin; reacts with mouse, rat and human. Detects a band of $37 \mathrm{kDa}$ by WB.

- Rabbit polyclonal anti-beta Actin (Abcam, \#ab8227, RRID:AB_2305186), affinity purified IgG. Raised against a synthetic peptide within Human beta Actin aa 1-100. The exact sequence is proprietary. Reacts with many species including mouse, rat and human. Detects a band of $42 \mathrm{kDa}$ by WB.

- Polyclonal goat anti-rabbit IgG H\&L (Abcam, \#ab97051, RRID:AB_10679369), affinity purified, horseradish peroxidase-conjugated. Specificity for rabbit IgG, with light chains common to other rabbit immunoglobulins. Detects a band of $~ 125 \mathrm{kDa}$ by WB.

- Polyclonal rabbit anti-goat IgG (Dako, \#P0449, RRID:AB_2617143), affinity-isolated, solidphase absorbed, horseradish peroxidase-conjugated. Specificity for goal immunoglobulins, mainly IgG, isolated from goat serum.

- Monoclonal anti-NeuN (Millipore, \#MAB377, RRID:AB_2298772), purified mouse IgG1, clone A60. Raised against purified cell nuclei from mouse brain. Reacts with many species including mouse, rat, human and avian. Detects 2-3 bands in the 46-48 kDa range by WB.

- Polyclonal goat anti-Iba1 (Abcam, \#ab5076, RRID:AB_2224402), affinity purified IgG. Raised against a synthetic peptide corresponding to human Iba1 aa 135-147 (C-terminal). Reacts with many species including rabbit, guinea pig, human and mouse. Detects a band of 17 kDa by WB. 
- Monoclonal mouse anti-GFAP (Millipore, \#MAB360, RRID:AB_11212597), clone GA5, unpurified IgG1. Raised against purified GFAP from porcine spinal cord. Reacts with many species including mouse, rat and human. Detects a band of $~ 51$ kDa by WB; no crossreactivity with vimentin.

- Polyclonal donkey anti-rabbit IgG (H+L) Alexa Fluor 594 (Invitrogen, \#A-21207, RRID:AB_141637), highly cross-absorbed secondary antibody, purified. Raised against rabbit gamma immunoglobulins, heavy and light chains.

- Polyclonal donkey anti-goat IgG (H+L) Alexa Fluor 488 (Invitrogen, \#A-11058, RRID:AB_2534105), highly cross-absorbed secondary antibody, purified. Raised against goat gamma immunoglobulins, heavy and light chains. Cross-absorbed against rabbit rat, mouse and human IgG.

- Polyclonal donkey anti-mouse Alexa Fluor 488 (Invitrogen, \#A-21202, RRID:AB_141607), highly cross-absorbed secondary antibody, purified. Raised against mouse gamma immunoglobulins, heavy and light chains.

Positive controls were tissues with known expression of proteins of interest (e.g. brain tissue expressing GFAP, NeuN and Iba1). Negative or secondary antibody controls (e.g. omission of the primary antibody) were used to demonstrate that labeling observed was due only to binding of the secondary antibody to the primary, and were run in parallel to positive staining in each experiment.

\section{6 Cytosolic/Nuclear separation}

Half of the frozen tissue was allocated for cytosol and nuclear separation of proteins. Tissue was manually homogenized on ice, then incubated for $10 \mathrm{~min}$ in $200 \mu \mathrm{l}$ of Cell Lysis buffer (10 mM HEPES, $10 \mathrm{mM} \mathrm{NaCl}, 1 \mathrm{mM} \mathrm{KH_{2 } \mathrm { PO } _ { 4 } , 5 \mathrm { mM } \mathrm { NaHCO }}$, 5 mM EDTA, $1 \mathrm{mM} \mathrm{CaCl}$, $0.5 \mathrm{mM} \mathrm{MgCl}_{2}$ ) with $1 \%$ Triton $\mathrm{X}-100$. The suspension was then spun at $13000 \mathrm{rpm}$ for $10 \mathrm{~min}$ at $4{ }^{\circ} \mathrm{C}$. The 
supernatant was collected, an equal volume of 5\% sodium dodecyl sulfate (SDS) was added, then the suspension was boiled for $5 \mathrm{~min}$ at $100{ }^{\circ} \mathrm{C}$ to complete preparation of the cytoplasmic and extracellular proteins. The remaining pellet was resuspended in $200 \mu \mathrm{l}$ of TSE buffer (10 mM Tris, $300 \mathrm{mM}$ sucrose, $1 \mathrm{mM}$ EDTA, $1 \%$ Triton $\mathrm{X}-100, \mathrm{pH} 7.5$ ), and spun at $4000 \mathrm{~g}$ for $5 \mathrm{~min}$ at $4{ }^{\circ} \mathrm{C}$. The supernatant was then removed. This was repeated three times and the final pellet was combined with $100 \mu 15 \%$ SDS, then boiled for $5 \mathrm{~min}$ at $100{ }^{\circ} \mathrm{C}$ to complete the preparation of the nuclear proteins. The remaining tissue was prepared for total protein quantification. Tissue was manually homogenized on ice, then incubation in radioimmunoprecipitation assay buffer (Alcaraz et al., 1990) containing protease and phosphatase inhibitors (Sigma) for $10 \mathrm{~min}$. These were then spun down at $13000 \mathrm{rpm}$ for 20 min at $4^{\circ} \mathrm{C}$. Total protein content in the supernatant was quantified by BCA assay (Pierce BCA quantification kit) and all samples were diluted to $1 \mathrm{mg} / \mathrm{ml}$.

\section{2. $7 \quad$ Western blot}

$10 \mu \mathrm{g}$ of protein was incubated in loading dye at $100{ }^{\circ} \mathrm{C}$, then loaded onto a $7.5 \%$ polyacrylamide gel, for separation by SDS-polyacrylamide gel electrophoresis (SDS-PAGE) using a Bio-Rad MiniProtean apparatus. They were then transferred to polyvinylidene difluoride membranes. The membranes were blocked in 5\% skim powdered milk and incubated with one of the following primary antibodies: anti-HMGB1 (\#ab18256 Abcam, 1:1000 for 24 h), anti-GFAP (\#Z033401-2, Dako 1:10,000, for 24 h), and anti-CD68 (\#ab31630 Abcam 1:500, for 24 h). Membranes were subsequently incubated with horseradish peroxidase-conjugated goat anti-rabbit (\#ab97051, Abcam, 1:60 000 for 1 h) or rabbit anti-goat (\#P0449 Dako, 1:2000 for 1.5 h) secondary antibodies. Density of bands was quantified with ImageJ (Heidebrecht et al., 2009). Values were normalized for protein loading to levels of house-keeping proteins GAPDH (\#sc-48166, Santa Cruz, 1:1000 overnight) or $\beta$-actin (\#ab8227, Abcam, 1:1000 overnight) and averaged per time point (n=7-8/group). 


\section{8 Enzyme-linked immunoabsorbent assay (ELISA)}

Cardiac blood samples were clotted at RT for $30 \mathrm{~min}$, then spun for 3 min at 10,000 rpm, and the supernatant retained as serum for storage at $-80^{\circ} \mathrm{C}$ until use. The concentration of HMGB1 was determined by a commercially available ELISA kit (\#IBST51011, IBL International), as per the manufacturer instructions.

\section{9 Immunofluorescence}

For immunofluorescence staining, sections were dewaxed by immersion in xylene and decreasing ethanol concentrations, followed by microwave antigen retrieval in $10 \mathrm{mM}$ citrate buffer containing 0.5\% Tween-20. Following blocking in 10\% normal donkey serum (NDS) and 0.1\% Triton-X100 in PBS, sections were incubated in a 5\% NDS/0.1\% Triton-X100/PBS solution overnight at $4{ }^{\circ} \mathrm{C}$ with primary antibodies as follows: rabbit polyclonal anti-HMGB1 (\#ab18256 Abcam, 1:1000) + mouse monoclonal anti-NeuN (\#MAB377 Millipore, 1:1000), or goat polyclonal anti-Iba1 (\#ab5076 Abcam, 1:750), or mouse monoclonal anti-GFAP (\#MAB360 Millipore, 1:1000). Primary antibodies were detected on day 2 by a 1 h room-temperature incubation with donkey anti-rabbit IgG AF 594 (for HMGB1), donkey anti-goat IgG AF 488 (for Iba1), or donkey anti-mouse AF 488 (for GFAP or NeuN). All secondary antibodies sourced from Invitrogen. After washing to remove excess solution, sections were incubated with $0.3 \%$ Sudan Black to reduce tissue auto-fluorescence, then cover-slipped with Vectashield Hard Set mounting media (Vector Laboratories).

For the qualitative assessment of both GFAP and Iba1 staining, one section was selected from a random animal per group, at $\sim-0.4 \mathrm{~mm}-0.7 \mathrm{~mm}$ Bregma, the site of the lesion where evident damaged tissue was observed. This location was chosen by an investigator blinded to age and 
injury/sham grouping, and based on determination of the lesion core from histological staining and subsequent tissue volume analyses (section 2.10). Selection of the field of view for qualitative evaluation of GFAP and Iba1 staining was performed by an investigator blinded to age and injury/sham grouping. The lesion encompassed the most evident region of tissue damage from the cortical surface; the perilesional neocortex was defined as one field of view lateral to this; and the CA1 and CA3 were identified by their neuroanatomical structures from DAPI staining. All images were captured at 20 or 40 x magnification using an Olympus IX81 fluorescent microscopy with IX2UCB camera and Olympus Cell^M software.

For qualitative assessment of HMGB1 cellular localization, captured images were pseudo-colored and channels were merged using ImageJ (Rasband, 1997-2018; Schneider et al., 2012). For quantification of HMGB1 extracellular release, $20 \mathrm{x}$ images of HMGB1 staining in the cortical lesion core, perilesional neocortex, and equivalent regions from the contralateral neocortex were calibrated and thresholded in ImageJ to a predetermined limit to create a mask. Using the analyze particle function, quantification of staining was limited to particles of 0-15 $\mu$ m diameter to omit HMGB1 nuclear staining (Feldman et al., 2012). The percent fluorescent area was then calculated and expressed relative to the average contralateral value for each region-of-interest. Three sections within the lesion core (350 $\mu \mathrm{m}$ apart) were quantified per brain ( $\mathrm{n}=6$ per group).

\subsection{Histology}

Volumetric estimation of the dorsal neocortex was performed on cresyl violet-stained sections collected at $3 \mathrm{~d}$ post-injury, to compare the extent of tissue loss after TBI in pediatric versus adult mice. The unbiased Cavalieri method was employed, using Stereo Investigator software with a Nikon BX51 microscope and QImaging camera (MicroBrightField, Williston, VT). Systematic random 
sampling was applied using a sampling interval of 25, a 4 x objective and a grid size of $100 \mu \mathrm{m}$. Measurements were restricted to the dorsal hemispheres, defined by an inferior horizontal boundary line perpendicular to the most ventral point of the 3rd ventricle at the midline as described previously (Semple et al., 2015). The Gundersen mean coefficient of error $(m=0)$ for individual estimates was maintained $\leq 0.08$, and group means are expressed as estimated volume $\left(\mathrm{mm}^{3}\right)$.

\section{11 Statistical analysis}

Data analysis was performed using GraphPad Prism version 6.07. Parametric analyses were used for all data after confirming normal distribution by D’Agostino-Pearson's normality test. Outliers were identified as values greater than 2 standard deviations from the mean and were excluded from analysis. Data are expressed as group means \pm standard error of the mean (SEM). Differences among groups for each age group was analyzed by analysis of variance (ANOVA) with post-hoc Bonferroni or Tukey tests as appropriate (Tukey's test when data fulfilled the assumption of equal variance within groups). Comparison between pediatric and adult data was performed by expressing each age group as a fold change relative to their age-matched sham controls, then direct comparison between these values by unpaired t-tests. Statistical significance was defined as $\mathrm{p}<0.05$.

\section{Results}

\subsection{Microglia/macrophages and astrocyte activation are differentially activated across an acute} time course after pediatric versus adult TBI

The cellular neuroinflammatory response, involving the activation and migration of astrocytes and microglia as well as infiltration of peripheral-derived leukocytes such as macrophages, was firstly visualized in the brains of pediatric and adult mice, at 3 days after sham and TBI. Iba1, a general marker of microglia and macrophages (Ito et al., 1998), was detected throughout the brains of sham 
mice, as expected, in cells with a ramified resting stage morphology (Figure 1A). At $3 \mathrm{~d}$ after TBI in both adult and pediatric mice, a considerable increase in Iba1 staining was observed in both the lesion and perilesional neocortex areas, as well as in the hippocampus, in particular the dentate gyrus (DG). The astrocytic marker GFAP was visualized as an indicator of astrocytic activation (Eng \& Dearmond, 1983). From representative immunofluorescence staining, GFAP expression in the brains of sham mice was below detection in cortical astrocytes; while in the hippocampus, staining revealed GFAP+ cells in the CA1 and hilus of the DG (Figure 1B). At $3 \mathrm{~d}$ after TBI in both the adult and pediatric brain, a robust increase in GFAP+ staining intensity was observed in both the perilesional neocortex and hippocampus.

To quantify the magnitude of this cellular inflammatory response, we turned to Western blotting of samples collected across an acute time course of the first week post-TBI compared to age-matched sham controls. ED1 was used as a marker of activated microglia and macrophages (Ziebell et al., 2015). In the adult brain, ED1 levels were significantly elevated at 3 d post-injury, which was sustained to $7 \mathrm{~d}$ at up to 10 -fold compared to sham levels $\left(\mathrm{F}_{5,42}=6.384, \mathrm{p}<0.001\right.$, Figure $\left.2 \mathrm{~A}\right)$. In contrast, in pediatric tissue, ED1 levels were significantly elevated at $2 \mathrm{~h}$ to approximately 30 -fold compared to sham levels $\left(\mathrm{F}_{5,39}=7.589, \mathrm{p}<0.0001\right.$, Figure 2C). Although ED1 appeared to remain elevated at $24 \mathrm{~h}$ and $3 \mathrm{~d}$, this did not reach statistical significance relative to sham controls. GFAP was also quantified by Western blot across the time course. In adult mice, GFAP levels were significantly elevated at $3 \mathrm{~d}$ post-injury to approximately 1.5-fold relative to sham levels, which persisted to at least $7 \mathrm{~d}\left(\mathrm{~F}_{6,49}=4.650, \mathrm{p}<0.001\right.$, Figure 2B). An earlier increase was observed in the pediatric neocortex compared to the injured adult brain, with a significant increase compared to sham levels observed at $24 \mathrm{~h}$ post-injury ( $>00.05$, Figure 2D). By $3 \mathrm{~d}$ post-injury, this increase was more pronounced than in the adult brain, at approximately 2 -fold compared to sham $\left(\mathrm{F}_{5,42}=30.67, \mathrm{p}<0.0001\right)$. 


\subsection{Comparable ipsilateral tissue loss at $3 d$ post-TBI in the pediatric and adult brain}

We considered the possibility that the above-mentioned differences observed between pediatric and adult mice in their post-injury inflammatory profiles could potentially be attributed to a difference in injury severity, in spite of consistent injury parameters performed for both cohorts. To assess this, we performed cresyl violet staining to evaluate the lesion size, by quantification of the degree of tissue loss in the ipsilateral neocortex compared to contralateral neocortex in TBI mice (Figure 3). There was considerable ipsilateral cortical loss as compared to the contralateral neocortex, which was observed in both pediatric (unpaired t-test, $\mathrm{p}<0.05)$ and adult brains $(\mathrm{p}<0.005)$. When expressed as percentage tissue loss (ipsilateral/ contralateral), both pediatric and adult cohorts showed a comparable degree of tissue loss of approximately 15-20\% (unpaired t-test, $\mathrm{p}=0.35$ ).

\subsection{HMGB1 is released into the extracellular space after TBI in both the pediatric and adult brain}

Immunofluorescence staining was used to assess the local presence and distribution of HMGB1 in the brains of sham and TBI mice. In sham (uninjured) brains, widespread expression of HMGB1 was evident in the neocortex and hippocampus, particularly in DG granule cells, CA1 and cortical pyramidal neurons, identified by co-labeling with the neuronal marker NeuN (Figure 4A). Expression was also evident in non-NeuN+ cells, such as the sub-ventricular zone of the DG (likely immature neurons), the DG hilus, and throughout the neocortex and CA1 (likely other cell types, such as microglia, astrocytes and oligodendrocytes). At $3 \mathrm{~d}$ after TBI, cellular HMGB1 staining was still evident, but coincided with an increase in extracellular HGMB1 staining, both in a diffuse manner as well as small particles of fluorescent staining (Figure 4B). NeuN+ neurons were sparse in lesion core, and those that remain were strikingly absent of HMGB1 labeling. In other regions more distal to the lesion core (e.g. the pericontusional neocortex, ipsilateral corpus callosum and medial suprapyramidal 
layer of the ipsilateral DG granule cell layer), neuronal damage was evident as a reduction in NeuN+ cells as well as abnormal morphology or disrupted structural organization. While there appeared to be more HMGB1 staining in these regions compared to in the lesion core, little co-localization between HMGB1 and NeuN was present. Together, these observations suggest that, after both pediatric and adult TBI, neuronal damage is associated with a release of HMGB1 into the extracellular space.

We quantified the amount of extracellular HMGB1 staining in the lesion and perilesional neocortex after adult and pediatric TBI, defined as fluorescence that was clearly not associated with a cell (particles $<15 \mu \mathrm{m}$ diameter), as described in section 2.8 (Figure 5A). After TBI in pediatric mice, quantification confirmed a significant increase in extracellular HMGB1 in both lesional (t-test, $\mathrm{p}<0.005$ ) and perilesional $(\mathrm{p}<0.05)$ neocortex compared to sham controls (Figure 5B, C). After TBI in adult mice, there was also an increase of HMGB1 extracellular staining compared to their respective shams; however, this reached statistical significance only in the perilesional neocortex $(p<0.05$, Figure 5D-E). To compare between injury to the pediatric versus adult brain, we expressing the data for TBI animals at each age relative to their age-matched sham controls, and then directly compared the fold change values. This analysis revealed significantly more extracellular HMGB1 staining in the lesion core of pediatric TBI mice compared to adult TBI mice (5.5 \pm 1.1 versus $2.5 \pm 0.9$ fold change, respectively; unpaired t-test, $\mathrm{p}<0.05)$. The extent of HMGB1 release in the pericontusional neocortex was comparable between pediatric and adult mice (3.4 \pm 1.1 versus $2.7 \pm 0.6$ fold change, respectively; unpaired t-test, $\mathrm{p}=0.60$ ).

Finally, we quantified HMGB1 by Western blot across the acute time course after TBI, in the pediatric and adult mouse brain, both in terms of total protein levels as well as the nuclear and cytosolic fractions. HMGB1 levels in the injured neocortex was significantly increased at $3 \mathrm{~d}$ postinjury in total protein in adult animals $\left(\mathrm{F}_{6,48}=3.160, \mathrm{p}<0.05\right.$, Figure $\left.6 \mathrm{~A}\right)$. However, we observed only a 
non-significant trend towards increased HMGB1 protein at $2 \mathrm{~h}$ and $3 \mathrm{~d}$ post-TBI in the cytosolic fraction ( $p=0.07$, Figure 6B). Surprisingly, no significant differences in HMGB1 protein levels (either total, cytosolic or nuclear) were detected after TBI in pediatric mice, although there was a trend towards reduced HMGB1 at $7 \mathrm{~d}$ post-TBI compared to sham controls in all preparations ( $\mathrm{p}=0.06$, Figure 6D-F).

\subsection{HMGB1 is increased acutely in serum from pediatric but not adult mice after TBI}

The concentration of HMGB1 in peripheral serum after TBI was analyzed by ELISA. There was a robust increase at $2 \mathrm{~h}$ post injury of about 1.75-fold to sham in the pediatric brain (one-way ANOVA $\mathrm{F}_{5,32}=3.115, \mathrm{p}<0.05$, Figure $7 \mathrm{~A}$ ). In contrast, HMGB1 levels in adult mice remained stable relative to sham levels for up to 7 days post-injury $\left(\mathrm{F}_{5,40}=1.98\right.$, $\mathrm{p}=0.11$ Figure $\left.7 \mathrm{~B}\right)$. Of note, we also observed a higher baseline (sham) level of HMGB1 in pediatric serum (20.79 \pm 3.30$)$ compared to in adult serum (9.19 \pm 0.43; unpaired t-test, $\mathrm{p}<0.001$ ), consistent with previous studies (Enokido et al., 2008). To compare between injury to the pediatric versus adult brain, we expressing the data for TBI animals at each time point, in each age group, relative to their age-matched sham controls, and then directly compared the fold change values. Two-way ANOVA revealed a significant main effect of time postinjury $\left(\mathrm{F}_{4,53}=3.29, \mathrm{p}=0.02\right)$ but no effect of age $\left(\mathrm{F}_{4,53}=1.36\right.$, $\left.\mathrm{p}=0.21\right)$ nor an interaction $\left(\mathrm{F}_{1,53}=1.59\right.$, $\mathrm{p}=0.26$ ). Of note, Bonferroni’s post-hoc analyses found a significantly difference between serum HMGB1 levels at $2 \mathrm{~h}$ compared to $6 \mathrm{~h}$ and $7 \mathrm{~d}$ post-injury in the pediatric brain $(\mathrm{p}<0.05)$, but no significant changes over time post-injury in the adult brain (data not shown). Together, these findings confirm the presence of HMGB1 in peripheral serum acutely after TBI to the pediatric but not adult brain.

\section{Discussion:}

This article is protected by copyright. All rights reserved. 


\subsection{Summary of findings}

In this study, we aimed to characterize the relative levels of HMGB1 and key inflammatory cell responses after experimental TBI in mice, in both the pediatric and adult brain. After TBI in the pediatric brain, we found an early and robust increase in astrocytes and microglia/macrophages within hours of the injury. We observed a local increase in extracellular HMGB1 in the ipsilateral neocortex at $3 \mathrm{~d}$ post-injury by immunofluorescence, although this was not reflected by any changes in global expression levels detected by Western blotting. There was also an early and robust increase in serum HMGB1 by $2 \mathrm{~h}$ post-injury. After TBI in the adult brain, there was also an increase in astrocytes and microglia/macrophage reactivity relative to their sham controls, albeit not as robust in magnitude as the response in pediatric mice, and this cellular inflammatory response was delayed in onset to $3 \mathrm{~d}$ post-injury, consistent with other studies in adult animals (Kreutzberg, 1996; Webster et al., 2017). While there was no increase in serum HMGB1 in the adult injured brain, we did observe localized extracellular release of HMGB1 in the injured neocortex at $3 \mathrm{~d}$ after TBI. These results corroborate and extend upon previous studies that demonstrate a differential post-injury inflammatory response between immature and adult humans and experimental animals (Butovsky et al., 2014; Copland et al., 2004; Giza et al., 2007; Schultz et al., 2004). For example, the presence of leukocytes in the brain has been reported to vary depending on age, with higher levels in the brains of animals aged 1-3 weeks compared to adults, which suggests that the pro-inflammatory response to a TBI during early life is more pronounced than in the adult (Anthony et al., 1997; Claus et al., 2010; Lawson \& Perry, 1995).

\subsection{Differential inflammatory responses despite comparable injuries to the pediatric and adult} In this study, we used 3 week old mice as a model of TBI to the pediatric brain, based upon neuroanatomical, biochemical, and behavioral evidence indicating that this age equates to a toddleraged child (Semple et al., 2013). Previous studies have also shown that by this developmental age, the 
brain has reached 90-95\% adult weight (Dekaban \& Sadowsky, 1978; Dobbing \& Sands, 1973, 1979; Giedd et al., 1999). Based on this, we chose to use the same injury parameters for both the pediatric and adult cohorts, rather than attempt to arbitrarily scale the impact based on age (Prins \& Hovda, 2003). With this in mind, we a priori designed the experiments to consider injury to the pediatric and adult brains independently, relative to their respective sham controls. We confirmed by cresyl violet staining that this approach generated a comparable injury in both pediatric and adult TBI mice, at least within the acute post-injury phase, with a similar degree of tissue loss evident by $3 \mathrm{~d}$ (Figure 3).This suggests that any differences observed in the neuroinflammatory are a result of developmental age-ofinsult, rather than a consequence of differential injury severities. Our findings in the pediatric brain are also unlikely to manifest from immaturity of the inflammatory cells themselves, as both astrocytes and microglia are reportedly fully matured by this age in rodents p5 in rodents (Bilimoria \& Stevens, 2015; Chaboub \& Deneen, 2013). Instead, we speculate that observed age-dependent differences in the magnitude of reactivity after TBI are due to developmental differences in how the cells respond to insult. The robust, early increase in ED1 in the pediatric brain specifically was unexpected, and contrasts strikingly with the delayed increase in ED1 observed in the adult brain. Although we have not explored this finding further in the current study, reports of more abundant circulating macrophages in the immature brain compared to the adult under basal conditions (Perry et al., 1985; Unkeless, 1979) may underlie this finding, as mechanical disruption of the BBB at such an acute postinjury time may allow these cells to then influx in large numbers. Differences in the cellular neuroinflammatory response may also be attributed to age-dependent differences in BBB damage after TBI, based on previous evidence that more extensive breakdown of the BBB occurs in the pediatric brain compared to the adult after a pro-inflammatory insult (Anthony et al., 1998; Anthony et al., 1997). Of note, such age-dependent differences are not without precedence - other studies have reported an age-dependent temporal pattern of infiltrating leukocytes, with greater numbers of CD45+ 
leukocytes in the pediatric brain after TBI compared to the adult, that lingered for a prolonged period of injury (Claus et al., 2010). Future studies utilizing flow cytometry to profile distinct populations of cells of the monocyte-lineage, in both the periphery as well as the CNS, are needed to next validate and interpret these findings.

\subsection{HMGB1 release after experimental TBI}

HMGB1 is released in the CNS through two mechanisms; passively, from dying neurons immediately after an injury, or actively, from various inflammatory cells upon activation (Bonaldi et al., 2003; Lu et al., 2012; Scaffidi et al., 2002; Wang et al., 1999). Many cell types that have been identified to release HMGB1 in the CNS include neurons, microglia, natural killer cells, platelets, dendritic cells, macrophages and monocytes (Harris et al., 2012). Co-labeling with NeuN, a marker of mature neurons, demonstrates that a large proportion of mouse neurons in both the neocortex and hippocampus express HGMB1 under basal conditions, and appear to lose this immunoreactivity by 3 d post-injury (Figure 4). Studies of ischemia have shown an increase in serum HMGB1, attributed to CNS release, at $4 \mathrm{~h}$ post-injury in adult mice, which corresponded to a local decrease in HMGB1 in the brain (Kim et al., 2008; Kim et al., 2006). In the current study, we found a robust increase in HMGB1 in the serum of pediatric mice after TBI relative to their sham controls, which was intriguingly not evident in the adult brain (Figure 7). Of note, we also observed higher baseline (sham) levels of HMGB1 in the serum of pediatric mice compared to adult mice - consistent with previous research, whereby the highest basal protein expression of HMGB1 in reportedly at 2 weeks of age, before decreasing at adulthood (Enokido et al., 2008).

Within the brain, several previous studies using experimental TBI models in adult rodents have demonstrated an acute reduction in HMGB1-expressing cells within the first few days after injury 
(Gao et al., 2012). In contrast, other studies using a similar injury model to the current experiments have reported an increase in HMGB1 at $24 \mathrm{~h}$, restricted to the cytosolic protein fraction, suggestive of translocation of the protein from the nucleus (Simon et al., 2018). These previous studies differ from our current findings using Western blotting of cortical tissue, whereby we observed an increase in total HMGB1 protein at $3 \mathrm{~d}$ after TBI in the adult brain only, which was not reflected in the cytosolic/nuclear fractionated samples (Figure 6). Surprisingly, we also failed to detect any changes in global HMGB1 levels by Western blot in the pediatric brain after TBI. These results may be due to the very acute release of HMGB1 after TBI in our model, perhaps prior to our earliest time point of 2 h post-injury. Another explanation may be the nature of the injury itself, whereby a more severe or diffuse insult to the brain may be necessary to induce widespread loss of neurons to produce sufficient quantities of HMGB1 release and/or nuclear to cytosol translocation to be detected by Western blot. Thirdly, Western blotting may not be a sensitive enough measure to quantify changes in cellular localization of this protein. We speculate that this is the most likely explanation, as immunofluorescence staining of tissue at $3 \mathrm{~d}$ post-injury (Figures 4-5) clearly demonstrated a robust but localized release of extracellular HMGB1.

Little data exists on the expression of HMGB1 in the context of TBI to the pediatric brain. Prompting our experimental study was previous clinical evidence that HMGB1 levels after TBI in a pediatric cohort were inversely correlated with Glasgow Outcome Scores at 6 months post-injury, with higher levels being associated with poorer functional outcomes (Au et al., 2012). Secondly, in a recent experimental rat model of pediatric TBI, HMGB1 was quantified as a marker of inflammation to evaluate the effect of minocycline treatment; however, levels were only measured at $24 \mathrm{~h}$, with this time point justified based on previous data from adult rodents (Simon et al., 2018). As such, to our 
knowledge, this is the first study to investigate the expression of HMGB1 across an acute time course after pediatric experimental TBI, and to incorporate both peripheral (serum) and CNS measures.

\subsection{HMGB1 - a symptom or source of inflammatory activation?}

HMGB1 may be both a cause and consequence of immune cell activation after TBI in the adult and pediatric brain. As mentioned above, many CNS cell types may be the source of HMGB1 following an inflammatory challenge or insult (Bonaldi et al., 2003; Gardella et al., 2002; Wang et al., 1999). We propose that mature neurons, damaged both by the initial mechanical insult of TBI as well as secondary injury processes, are a key source of HMGB1, based on our immunofluorescence observations (Figure 4). In addition, we observed an acute increase in ED1 in the injured pediatric brain (Figure 2), suggesting a robust infiltration of macrophages from the periphery, at $2 \mathrm{~h}$ postinjury, a time that corresponds with the observed increase in serum HMGB1 (Figure 7). It is therefore likely that infiltrated macrophages are a key source of HMGB1 release in this context. Thirdly, there is also a wealth of evidence indicating that astrocytes can also release HMGB1 (Hayakawa et al., 2012; Kim et al., 2008; Ning et al., 2011; Passalacqua et al., 1998). Glial-derived HMGB1 appears to promote brain edema after TBI, as experimental inhibition of HMGB1 has been shown to attenuate both edema and associated cellular neuroinflammation (Ohnishi et al., 2014).

The relationship between HMGB1 and glial activation, however, is a bi-directional one; glial cells not only release HMGB1 but are also the target of this mediator. Previous studies have shown that blocking HMGB1 expression reduces microglial activation after cerebral ischemic injury or lipopolysaccharide challenge in the adult brain, associated with a reduction in pro-inflammatory cytokines (Kim et al., 2006; Lee et al., 2014). The ability of HMGB1 to stimulate astrocyte activation 
is likely to be indirect, via its activity as a damage-associated molecular pattern to initiate proinflammatory cytokine release, which in turn promotes astrocyte activation (Yang et al., 2012).

\subsection{Clinical implications of age-dependent differences in neuroinflammation after TBI}

Analysis of blood and CSF samples from TBI patients have provided insight into the systemic inflammatory response after injury, revealing a rapid and acute increase in levels of several proinflammatory cytokines (Csuka et al., 1999; Fassbender et al., 2000; Morganti-Kossman et al., 1997). Although less well-characterized, elevation of several inflammatory cytokines have also been reported in children 1 day after injury (Bell et al., 1997). Unfortunately, differences in analysis techniques, controls, and reporting render it challenging to compare existing studies, to address the question of whether age at insult plays a role in the magnitude and profile of this inflammatory response. In addition, it is difficult to examine the cellular inflammatory response in vivo in a patient cohort. However, some evidence does suggest that an early age at the time of injury results in increased vulnerability to both neuroinflammation and poor outcomes. For example, IL-6 levels in adults do not appear to predict TBI outcomes, yet in a pediatric population, elevated IL-6 levels were found to correlate with improved functional outcomes (Chiaretti et al., 2008). Conversely, levels of HMGB1 in the pediatric brain have been found to correlate with poorer outcomes in infants and children, as mentioned earlier (Au et al., 2012). Bringing together these clinical findings, alongside accumulating evidence from our current study and others of age-related differences in the inflammatory response (Anthony et al., 1997; Claus et al., 2010; Lawson \& Perry, 1995), as well as the trajectory of secondary injury progression and recovery reported after TBI to the developing brain (Claus et al., 2010), we postulate that the unique neuroinflammatory state after pediatric TBI is a key determinant of long-term outcomes in the population. 
This study corroborated previous findings of age-dependent differences in the inflammatory response after neurotrauma and highlights the ongoing need for focused experimental research into secondary injury mechanisms at different developmental ages across the life span. Such findings will continue to inform clinical practice guidelines on how best to manage pediatric patients and may have profound implications for how we target and treat secondary injury mechanisms (Adelson et al., 2003; Bennett, 2014). Novel therapeutics demonstrating efficacy in targeting specific aspects of the inflammatory cascade are ongoing in adult experimental research, but differential responses to injury depending on age at insult suggests that these approaches may not necessarily translate to children.

HMGB1 is considered a key early responder and recruiter of pro-inflammatory mediators during an inflammatory response. Several studies have demonstrated neuroprotection afforded by the inhibition or blocking of HMGB1 in experimental models of ischemia, TBI and subarachnoid hemorrhage in adult rodents (Gong et al., 2012; Ieong et al., 2018; Okuma et al., 2014; Okuma et al., 2012; Zhang et al., 2011). These models focus almost exclusively on injury to the adult brain, and there are few that consider the expression, release and potential modulation of HMGB1 in the pediatric context (Simon et al., 2018). Due to the age-dependent differences found in this study, both in terms of HMGB1 release as well as temporal changes in inflammatory cell activation after TBI, future studies aiming to inhibit HMGB1 in pediatric TBI models will provide greater understanding to the role of HMGB1 in this context. Together, these findings suggest that the developing brain has exciting potential for strategies targeting HMGB1 to prevent the detrimental effects of neuroinflammation after pediatric TBI. 


\section{References:}

ABS. (2004). Disability, ageing and carers: summary of findings, Australia 2003. Canberra: ABS (Australian Bureau of Statistics).

Adelson, P. D., Bratton, S. L., Carney, N. A., Chesnut, R. M., du Coudray, H. E. M., Goldstein, B., . . . Critical Care, S. (2003). Guidelines for the acute medical management of severe traumatic brain injury in infants, children, and adolescents. Chapter 1: Introduction. Pediatric critical care medicine : a journal of the Society of Critical Care Medicine and the World Federation of Pediatric Intensive and Critical Care Societies, 4(3 Suppl), S2-4. doi:10.1097/01.ccm.0000066600.71233.01

Adelson, P. D., Clyde, B., Kochanek, P. M., Wisniewski, S. R., Marion, D. W., \& Yonas, H. (1997). Cerebrovascular response in infants and young children following severe traumatic brain injury: A preliminary report. Pediatric Neurosurgery, 26(4), 200-207.

Alcaraz, C., De Diego, M., Pastor, M. J., \& Escribano, J. M. (1990). Comparison of a radioimmunoprecipitation assay to immunoblotting and ELISA for detection of antibody to African swine fever virus. Journal of veterinary diagnostic investigation : official publication of the American Association of Veterinary Laboratory Diagnosticians, Inc, 2(3), 191-196.

Anderson, V., Catroppa, C., Morse, S., Haritou, F., \& Rosenfeld, J. (2005). Functional plasticity or vulnerability after early brain injury? Pediatrics, 116(6), 1374-1382. doi:10.1542/peds.20041728

Anthony, D., Dempster, R., Fearn, S., Clements, J., Wells, G., Perry, V. H., \& Walker, K. (1998). CXC chemokines generate age-related increases in neutrophil-mediated brain inflammation and blood-brain barrier breakdown. Current Biology, 8(16), 923-926. doi:10.1016/s09609822(07)00373-9

This article is protected by copyright. All rights reserved. 
Anthony, D. C., Bolton, S. J., Fearn, S., \& Perry, V. H. (1997). Age-related effects of interleukin-1 beta on polymorphonuclear neutrophil-dependent increases in blood-brain barrier permeability in rats. Brain, 120, 435-444. doi:10.1093/brain/120.3.435

Asensio, V. C., \& Campbell, I. L. (1999). Chemokines in the CNS: plurifunctional mediators in diverse states. Trends in neurosciences, 22(11), 504-512. doi:10.1016/s0166-2236(99)014538

Au, A. K., Aneja, R. K., Bell, M. J., Bayir, H., Feldman, K., Adelson, P. D., . . Clark, R. S. B. (2012). Cerebrospinal fluid levels of high-mobility group box 1 and cytochrome C predict outcome after pediatric traumatic brain injury. Journal of neurotrauma, 29(11), 2013-2021. doi:10.1089/neu.2011.2171

Bell, M. J., Kochanek, P. M., Doughty, L. A., Carcillo, J. A., Adelson, P. D., Clark, R. S., . . . DeKosky, S. T. (1997). Comparison of the interleukin-6 and interleukin-10 response in children after severe traumatic brain injury or septic shock. Acta neurochirurgica. Supplement, 70, 96-97.

Bennett, K. S. (2014). Adherence to the guidelines for management of severe pediatric traumatic brain injury: enough evidence to support benefit?*. Critical care medicine, 42(10), 2308-2309. doi:10.1097/ccm.0000000000000563

Berger, R. P., Ta'Asan, S., Rand, A., Lokshin, A., \& Kochanek, P. (2009). Multiplex Assessment of Serum Biomarker Concentrations in Well-Appearing Children With Inflicted Traumatic Brain Injury. Pediatric Research, 65(1), 97-102. doi:10.1203/PDR.0b013e31818c7e27

Bianchi, M. E., \& Manfredi, A. A. (2007). High-mobility group box 1 (HMGB1) protein at the crossroads between innate and adaptive immunity. Immunological reviews, 220, 35-46. doi:10.1111/j.1600-065X.2007.00574.X

This article is protected by copyright. All rights reserved. 
Bilimoria, P. M., \& Stevens, B. (2015). Microglia function during brain development: New insights from animal models. Brain Research, 1617, 7-17. doi:10.1016/j.brainres.2014.11.032

Bittigau, P., Sifringer, M., Felderhoff-Mueser, U., \& Ikonomidou, C. (2004). Apoptotic neurodegeneration in the context of traumatic injury to the developing brain. Experimental and Toxicologic Pathology, 56(1-2), 83-89. doi:10.1016/j.etp.2004.04.006

Bonaldi, T., Talamo, F., Scaffidi, P., Ferrera, D., Porto, A., Bachi, A., . . Bianchi, M. E. (2003). Monocytic cells hyperacetylate chromatin protein HMGB1 to redirect it towards secretion. Embo Journal, 22(20), 5551-5560. doi:10.1093/emboj/cdg516

Butovsky, O., Jedrychowski, M. P., Moore, C. S., Cialic, R., Lanser, A. J., Gabriely, G., . . Weiner, H. L. (2014). Identification of a unique TGF-beta-dependent molecular and functional signature in microglia. Nature Neuroscience, 17(1), 131-143. doi:10.1038/nn.3599

Buttram, S. D. W., Wisniewski, S. R., Jackson, E. K., Adelson, P. D., Feldman, K., Bayir, H., . . . Kochanek, P. M. (2007). Multiplex assessment of cytokine and chemokine levels in cerebrospinal fluid following severe pediatric traumatic brain injury: Effects of moderate hypothermia. Journal of neurotrauma, 24(11), 1707-1717. doi:10.1089/neu.2007.0349

Cederberg, D., \& Siesjo, P. (2010). What has inflammation to do with traumatic brain injury? Childs Nervous System, 26(2), 221-226. doi:10.1007/s00381-009-1029-x

Chaboub, L. S., \& Deneen, B. (2013). Astrocyte form and function in the developing central nervous system. Seminars in pediatric neurology, 20(4), 230-235. doi:10.1016/j.spen.2013.10.003

Chiaretti, A., Antonelli, A., Mastrangelo, A., Pezzotti, P., Tortorolo, L., Tosi, F., \& Genovese, O. (2008). Interleukin-6 and nerve growth factor upregulation correlates with improved outcome in children with severe traumatic brain injury. Journal of neurotrauma, 25(3), 225-234. doi:10.1089/neu.2007.0405

This article is protected by copyright. All rights reserved. 
Claus, C. P., Tsuru-Aoyagi, K., Adwanikar, H., Walker, B., Whetstone, W., \& Noble-Haeusslein, L. J. (2010). Age Is a Determinant of Leukocyte Infiltration and Loss of Cortical Volume after Traumatic Brain Injury. Developmental neuroscience, 32(5-6), 454-465. doi:10.1159/000316805

Copland, I. B., Martinez, F., Kavanagh, B. P., Engelberts, D., McKerlie, C., Belik, J., \& Post, M. (2004). High tidal volume ventilation causes different inflammatory responses in newborn versus adult lung. American journal of respiratory and critical care medicine, 169(6), 739748. doi:10.1164/rccm.200310-1417OC

Csuka, E., Morganti-Kossmann, M. C., Lenzlinger, P. M., Joller, H., Trentz, O., \& Kossmann, T. (1999). IL-10 levels in cerebrospinal fluid and serum of patients with severe traumatic brain injury: relationship to IL-6, TNF-alpha, TGF-beta1 and blood-brain barrier function. Journal of neuroimmunology, 101(2), 211-221. doi:10.1016/s0165-5728(99)00148-4

Dekaban, A. S., \& Sadowsky, D. (1978). Changes in brain weights during span of human life Relation of brain weights to body heights and body weights. Annals of Neurology, 4(4), 345356. doi:10.1002/ana.410040410

Dobbing, J., \& Sands, J. (1973). Quantitative grown and development of human brain. Archives of Disease in Childhood, 48(10), 757-767. doi:10.1136/adc.48.10.757

Dobbing, J., \& Sands, J. (1979). Comparative aspects of the brain growth spurt. Early Human Development, 3(1), 79-83. doi:10.1016/0378-3782(79)90022-7

Durkin, M. S., Olsen, S., Barlow, B., Virella, A., \& Connolly, E. S., Jr. (1998). The epidemiology of urban pediatric neurological trauma: evaluation of, and implications for, injury prevention programs. Neurosurgery, 42(2), 300-310. doi:10.1097/00006123-199802000-00052

This article is protected by copyright. All rights reserved. 
Elhofy, A., Wang, J., Tani, M., Fife, B. T., Kennedy, K. J., Bennett, J., . . Karpus, W. J. (2005). Transgenic expression of CCL2 in the central nervous system prevents experimental autoimmune encephalomyelitis. Journal of Leukocyte Biology, 77(2), 229-237.

Eng, L. F., \& Dearmond, S. J. (1983). Immunochemistry of the glial fibrillary acidic protein. Progress in Neuropathology, 5, 19-39.

Enokido, Y., Yoshitake, A., Ito, H., \& Okazawa, H. (2008). Age-dependent change of HMGB1 and DNA double-strand break accumulation in mouse brain. Biochemical and Biophysical Research Communications, 376(1), 128-133. doi:10.1016/j.bbrc.2008.08.108

Ewing-Cobbs, L., Prasad, M. R., Landry, S. H., Kramer, L., \& DeLeon, R. (2004). Executive functions following traumatic brain injury in young children: A preliminary analysis. Developmental Neuropsychology, 26(1), 487-512. doi:10.1207/s15326942dn2601_7

Fassbender, K., Schneider, S., Bertsch, T., Schlueter, D., Fatar, M., Ragoschke, A., . . Hennerici, M. (2000). Temporal profile of release of interleukin-1beta in neurotrauma. Neuroscience Letters, 284(3), 135-138. doi:10.1016/s0304-3940(00)00977-0

Feldman, P., Due, M. R., Ripsch, M. S., Khanna, R., \& White, F. A. (2012). The persistent release of HMGB1 contributes to tactile hyperalgesia in a rodent model of neuropathic pain. Journal of Neuroinflammation, 9. doi:180

10.1186/1742-2094-9-180

Ferriero, D. M., \& Miller, S. P. (2010). Imaging selective vulnerability in the developing nervous system. Journal of Anatomy, 217(4), 429-435. doi:10.1111/j.1469-7580.2010.01226.x

Galea, I., Bechmann, I., \& Perry, V. H. (2007). What is immune privilege (not)? Trends in immunology, 28(1), 12-18. doi:10.1016/j.it.2006.11.004

Gao, T.-L., Yuan, X.-T., Yang, D., Dai, H.-L., Wang, W.-J., Peng, X., ‥ F Fu, Z.-J. (2012). Expression of HMGB1 and RAGE in rat and human brains after traumatic brain injury. 
Journal of Trauma and Acute Care Surgery, 72(3), 643-649.

doi:10.1097/TA.0b013e31823c54a6

Gardella, S., Andrei, C., Ferrera, D., Lotti, L. V., Torrisi, M. R., Bianchi, M. E., \& Rubartelli, A. (2002). The nuclear protein HMGB1 is secreted by monocytes via a non-classical, vesiclemediated secretory pathway. EMBO reports, 3(10), 995-1001. doi:10.1093/emboreports/kvf198

Gerlitz, G., Hock, R., Ueda, T., \& Bustin, M. (2009). The dynamics of HMG protein-chromatin interactions in living cells. Biochemistry and Cell Biology, 87(1), 127-137. doi:10.1139/o08110

Giedd, J. N., Blumenthal, J., Jeffries, N. O., Castellanos, F. X., Liu, H., Zijdenbos, A., . . Rapoport, J. L. (1999). Brain development during childhood and adolescence: A longitudinal MRI study. Nature Neuroscience, 2(10), 861-863.

Giza, C. C., Mink, R. B., \& Madikians, A. (2007). Pediatric traumatic brain injury: not just little adults. Current Opinion in Critical Care, 13(2), 143-152.

doi:10.1097/MCC.0b013e32808255dc

Gong, G., Yuan, L.-b., Hu, L., Wu, W., Yin, L., Hou, J.-l., . . Zhou, L.-s. (2012). Glycyrrhizin attenuates rat ischemic spinal cord injury by suppressing inflammatory cytokines and HMGB1. Acta Pharmacologica Sinica, 33(1), 11-18. doi:10.1038/aps.2011.151

Harris, H. E., Andersson, U., \& Pisetsky, D. S. (2012). HMGB1: A multifunctional alarmin driving autoimmune and inflammatory disease. Nature Reviews Rheumatology, 8(4), 195-202. doi:10.1038/nrrheum.2011.222

Hayakawa, K., Pham, L.-D. D., Katusic, Z. S., Arai, K., \& Lo, E. H. (2012). Astrocytic high-mobility group box 1 promotes endothelial progenitor cell-mediated neurovascular remodeling during

This article is protected by copyright. All rights reserved. 
stroke recovery. Proceedings of the National Academy of Sciences of the United States of America, 109(19), 7505-7510. doi:10.1073/pnas.1121146109

Heidebrecht, F., Heidebrecht, A., Schulz, I., Behrens, S. E., \& Bader, A. (2009). Improved semiquantitative Western blot technique with increased quantification range. Journal of Immunological Methods, 345(1-2), 40-48. doi:10.1016/j.jim.2009.03.018

Ieong, C. C., Sun, H. G., Wang, Q. P., \& Ma, J. P. (2018). Glycyrrhizin suppresses the expressions of HMGB1 and ameliorates inflammative effect after acute subarachnoid hemorrhage in rat model. Journal of Clinical Neuroscience, 47, 278-284. doi:10.1016/j.jocn.2017.10.034

Ito, D., Imai, Y., Ohsawa, K., Nakajima, K., Fukuuchi, Y., \& Kohsaka, S. (1998). Microglia-specific localisation of a novel calcium binding protein, Iba1. Molecular Brain Research, 57(1), 1-9. doi:10.1016/s0169-328x(98)00040-0

Karpus, W. J., Lukacs, N. W., McRae, B. L., Strieter, R. M., Kunkel, S. L., \& Miller, S. D. (1995). An important role for the chemokine macrophage inflammatory protein-1 alpha in the pathogenesis of the T cell-mediated autoimmune disease, experimental autoimmune encephalomyelitis. Journal of immunology (Baltimore, Md. : 1950), 155(10), 5003-5010.

Keenan, H. T., \& Bratton, S. L. (2006). Epidemiology and outcomes of pediatric traumatic brain injury. Developmental neuroscience, 28(4-5), 256-263. doi:10.1159/000094152

Kieslich, M., Marquardt, G., Galow, G., Lorenz, R., \& Jacobit, G. (2001). Neurological and mental outcome after severe head injury in childhood: a long-term follow-up of 318 children. Disability and rehabilitation, 23(15), 665-669.

Kim, J.-B., Lim, C.-M., Yu, Y.-M., \& Lee, J.-K. (2008). Induction and subcellular localization of high-mobility group box-1 (HMGB1) in the postischemic rat brain. Journal of Neuroscience Research, 86(5), 1125-1131. doi:10.1002/jnr.21555

This article is protected by copyright. All rights reserved. 
Kim, J. B., Choi, J. S., Yu, Y. M., Nam, K., Piao, C. S., Kim, S. W., . . Lee, J. K. (2006). HMGB1, a novel cytokine-like mediator linking acute neuronal death and delayed neuroinflammation in the postischemic brain. Journal of Neuroscience, 26(24), 6413-6421. doi:10.1523/jneurosci.3815-05.2006

Koskiniemi, M., Kyykka, T., Nybo, T., \& Jarho, L. (1995). Long-term outcome after severe brian injury in preschoolers is worse than expected. Archives of Pediatrics \& Adolescent Medicine, 149(3), 249-254.

Kreutzberg, G. W. (1996). Microglia: a sensor for pathological events in the CNS. Trends in neurosciences, 19(8), 312-318. doi:10.1016/0166-2236(96)10049-7

Lawson, L. J., \& Perry, V. H. (1995). The unique characteristics of inflammatory responses in mouse brain are acquired during postnatal development. The European journal of neuroscience, 7(7), 1584-1595. doi:10.1111/j.1460-9568.1995.tb01154.x

Lee, S., Nam, Y., Koo, J. Y., Lim, D., Park, J., Ock, J., . . Park, S. B. (2014). A small molecule binding HMGB1 and HMGB2 inhibits microglia-mediated neuroinflammation. Nature chemical biology, 10(12), 1055-1060. doi:10.1038/nchembio.1669

Levi, L., Guilburd, J. N., Linn, S., \& Feinsod, M. (1991). The association between skull fracture, intracranial pathology and outcome in pediatric head-injury. British Journal of Neurosurgery, 5(6), 617-625. doi:10.3109/02688699109002885

Levy, O. (2007). Innate immunity of the newborn: basic mechanisms and clinical correlates. Nature Reviews. Immunology, 7(5), 379-390. doi:10.1038/nri2075

Lu, B., Nakamura, T., Inouye, K., Li, J., Tang, Y., Lundback, P., . . Tracey, K. J. (2012). Novel role of PKR in inflammasome activation and HMGB1 release. Nature, 488(7413), 670-674. doi:10.1038/nature11290

This article is protected by copyright. All rights reserved. 
Luo, Y., Fischer, F. R., Hancock, W. W., \& Dorf, M. E. (2000). Macrophage inflammatory protein-2 and KC induce chemokine production by mouse astrocytes. Journal of immunology (Baltimore, Md. : 1950), 165(7), 4015-4023.

Mazzola, C. A., \& Adelson, P. D. (2002). Critical care management of head trauma in children. Critical care medicine, 30(11 Suppl), S393-401. doi:10.1097/00003246-200211001-00003

Morganti-Kossman, M. C., Lenzlinger, P. M., Hans, V., Stahel, P., Csuka, E., Ammann, E., .. . Kossmann, T. (1997). Production of cytokines following brain injury: beneficial and deleterious for the damaged tissue. Molecular psychiatry, 2(2), 133-136. doi:10.1038/sj.mp.4000227

Morganti-Kossmann, M. C., Rancan, M., Stahel, P. F., \& Kossmann, T. (2002). Inflammatory response in acute traumatic brain injury: a double-edged sword. Current Opinion in Critical Care, 8(2), 101-105. doi:10.1097/00075198-200204000-00002

Ning, R. Z., Xiong, Y., Mahmood, A., Zhang, Y. L., Meng, Y. L., Qu, C. S., \& Chopp, M. (2011). Erythropoietin promotes neurovascular remodeling and long-term functional recovery in rats following traumatic brain injury. Brain Research, 1384, 140-150. doi:10.1016/j.brainres.2011.01.099

Ohnishi, M., Monda, A., Takemoto, R., Fujimoto, Y., Sugitani, M., Iwamura, T., . . Inoue, A. (2014). High-mobility group box 1 up-regulates aquaporin 4 expression via microglia-astrocyte interaction. Neurochemistry International, 75, 32-38. doi:10.1016/j.neuint.2014.05.007

Okuma, Y., Liu, K., Wake, H., Liu, R., Nishimura, Y., Hui, Z., . . Nishibori, M. (2014). Glycyrrhizin inhibits traumatic brain injury by reducing HMGB1-RAGE interaction. Neuropharmacology, 85, 18-26. doi:10.1016/j.neuropharm.2014.05.007

This article is protected by copyright. All rights reserved. 
Okuma, Y., Liu, K., Wake, H., Zhang, J., Maruo, T., Date, I., . . Nishibori, M. (2012). Anti-high mobility group box-1 antibody therapy for traumatic brain injury. Annals of Neurology, 72(3), 373-384. doi:10.1002/ana.23602

Passalacqua, M., Patrone, M., Picotti, G. B., DelRio, M., Sparatore, B., Melloni, E., \& Pontremoli, S. (1998). Stimulated astrocytes release high-mobility group 1 protein, an inducer of LAN-5 neuroblastoma cell differentiation. Neuroscience, 82(4), 1021-1028.

Perry, V. H., Hume, D. A., \& Gordon, S. (1985). Immunohistochemical localization of macrophages and microglia in the adult and developing mouse brain. Neuroscience, 15(2), 313-326. doi:10.1016/0306-4522(85)90215-5

Prins, M. L., \& Hovda, D. A. (2003). Developing experimental models to address traumatic brain injury in children. Journal of neurotrauma, 20(2), 123-137. doi:10.1089/08977150360547053

Prins, M. L., Lee, S. M., Cheng, C. L., Becker, D. P., \& Hovda, D. A. (1996). Fluid percussion brain injury in the developing and adult rat: a comparative study of mortality, morphology, intracranial pressure and mean arterial blood pressure. Brain research. Developmental brain research, 95(2), 272-282.

Rasband, W. S. (1997-2018). ImageJ. Bethesda, Maryland, USA: U.S. National Institutes of Health. Retrieved from http://imagej.nih.gov/ij/

Ryan, N. P., Anderson, V., Godfrey, C., Beauchamp, M. H., Coleman, L., Eren, S., . . Catroppa, C. (2014). Predictors of very-long-term sociocognitive function after pediatric traumatic brain injury: evidence for the vulnerability of the immature "social brain". Journal of neurotrauma, 31(7), 649-657. doi:10.1089/neu.2013.3153

Ryan, N. P., Catroppa, C., Cooper, J. M., Beare, R., Ditchfield, M., Coleman, L., . . Anderson, V. A. (2015). The emergence of age-dependent social cognitive deficits after generalized insult to

This article is protected by copyright. All rights reserved. 
the developing brain: A longitudinal prospective analysis using susceptibility-weighted imaging. Human Brain Mapping, 36(5), 1677-1691. doi:10.1002/hbm.22729

Scaffidi, P., Misteli, T., \& Bianchi, M. E. (2002). Release of chromatin protein HMGB1 by necrotic cells triggers inflammation. Nature, 418(6894), 191-195. doi:10.1038/nature00858

Schneider, C. A., Rasband, W. S., \& Eliceiri, K. W. (2012). NIH Image to ImageJ: 25 years of image analysis. Nature Methods, 9(7), 671-675. doi:10.1038/nmeth.2089

Schoderboeck, L., Adzemovic, M., Nicolussi, E.-M., Crupinschi, C., Hochmeister, S., Fischer, M.-T., ... Bradl, M. (2009). The "window of susceptibility" for inflammation in the immature central nervous system is characterized by a leaky blood-brain barrier and the local expression of inflammatory chemokines. Neurobiology of Disease, 35(3), 368-375. doi:10.1016/j.nbd.2009.05.026

Schultz, C., Temming, P., Bucsky, P., Gopel, W., Strunk, T., \& Hartel, C. (2004). Immature antiinflammatory response in neonates. Clinical and Experimental Immunology, 135(1), 130-136. doi:10.1111/j.1365-2249.2004.02313.x

Selassie, A. W., Zaloshnja, E., Langlois, J. A., Miller, T., Jones, P., \& Steiner, C. (2008). Incidence of long-term disability following traumatic brain injury hospitalization, United States, 2003. Journal of Head Trauma Rehabilitation, 23(2), 123-131. doi:10.1097/01.htr.0000314531.30401.39

Semple, B. D., Blomgren, K., Gimlin, K., Ferriero, D. M., \& Noble-Haeusslein, L. J. (2013). Brain development in rodents and humans: Identifying benchmarks of maturation and vulnerability to injury across species. Progress in neurobiology, 106-107, 1-16. doi:10.1016/j.pneurobio.2013.04.001

Semple, B. D., Noble-Haeusslein, L. J., Gooyit, M., Tercovich, K. G., Peng, Z., Nguyen, T. T., .. . Trivedi, A. (2015). Early Gelatinase Activity Is Not a Determinant of Long-Term Recovery 
after Traumatic Brain Injury in the Immature Mouse. Plos One, 10(11), e0143386. doi:10.1371/journal.pone.0143386

Simon, D. W., Aneja, R. K., Alexander, H., Bell, M. J., Bayir, H., Kochanek, P. M., \& Clark, R. S. B. (2018). Minocycline Attenuates High Mobility Group Box 1 Translocation, Microglial Activation, and Thalamic Neurodegeneration after Traumatic Brain Injury in Post-Natal Day 17 Rats. Journal of neurotrauma, 35(1), 130-138. doi:10.1089/neu.2017.5093

Stevenson, K. L., Skinner, J. C., Davis, D. S., Tran, M. P., Dixon, C. E., Kochanek, P. M., . . Adelson, P. D. (2000). Behavioral dysfunction in immature rats after controlled cortical impact (CCI). Journal of neurotrauma, 17(10), 944-944.

Stros, M. (2010). HMGB proteins: interactions with DNA and chromatin. Biochimica et biophysica acta, 1799(1-2), 101-113. doi:10.1016/j.bbagrm.2009.09.008

Thurman, D. J. (2016). The epidemiology of traumatic brain injury in children and youths: A review of research since 1990. Journal of Child Neurology, 31(1), 20-27. doi:10.1177/0883073814544363

Tian, J., Avalos, A. M., Mao, S.-Y., Chen, B., Senthil, K., Wu, H., . . Coyle, A. J. (2007). Toll-like receptor 9-dependent activation by DNA-containing immune complexes is mediated by HMGB1 and RAGE. Nature immunology, 8(5), 487-496. doi:10.1038/ni1457

Tong, W., Igarashi, T., Ferriero, D. M., \& Noble, L. J. (2002). Traumatic brain injury in the immature mouse brain: Characterization of regional vulnerability. Experimental Neurology, 176(1), 105-116. doi:10.1006/exnr.2002.7941

Umehara, F., Qin, Y. F., Goto, M., Wekerle, H., \& Meyermann, R. (1990). Experimental autoimmune encephalomyelitis in the maturing central-nervous-system - Transfer of myelin basic proteinspecific T-line lymphocytes to neonatal lewis rats. Laboratory Investigation, 62(2), 147-155.

This article is protected by copyright. All rights reserved. 
Unkeless, J. C. (1979). Characterization of a monoclonal antibody directed against mouse macrophage and lymphocyte Fc receptors. The Journal of experimental medicine, 150(3), 580-596. doi:10.1084/jem.150.3.580

Venereau, E., Casalgrandi, M., Schiraldi, M., Antoine, D. J., Cattaneo, A., De Marchis, F., . . Bianchi, M. E. (2012). Mutually exclusive redox forms of HMGB1 promote cell recruitment or proinflammatory cytokine release. The Journal of experimental medicine, 209(9), 15191528. doi:10.1084/jem.20120189

Venereau, E., Schiraldi, M., Uguccioni, M., \& Bianchi, M. E. (2013). HMGB1 and leukocyte migration during trauma and sterile inflammation. Molecular immunology, 55(1), 76-82. doi:10.1016/j.molimm.2012.10.037

Venters, B. J., \& Pugh, B. F. (2009). How eukaryotic genes are transcribed. Critical reviews in biochemistry and molecular biology, 44(2-3), 117-141. doi:10.1080/10409230902858785

Wang, H., Bloom, O., Zhang, M., Vishnubhakat, J. M., Ombrellino, M., Che, J., . . Tracey, K. J. (1999). HMG-1 as a late mediator of endotoxin lethality in mice. Science (New York, N.Y.), 285(5425), 248-251. doi:10.1126/science.285.5425.248

Webster, K. M., Sun, M., Crack, P., O'Brien, T. J., Shultz, S. R., \& Semple, B. D. (2017). Inflammation in epileptogenesis after traumatic brain injury. Journal of Neuroinflammation, 14(1), 10. doi:10.1186/s12974-016-0786-1

Whalen, M. J., Carlos, T. M., Kochanek, P. M., Wisniewski, S. R., Bell, M. J., Clark, R. S., . . Adelson, P. D. (2000). Interleukin-8 is increased in cerebrospinal fluid of children with severe head injury. Critical care medicine, 28(4), 929-934. doi:10.1097/00003246-20000400000003

This article is protected by copyright. All rights reserved. 
Yang, H., Antoine, D. J., Andersson, U., \& Tracey, K. J. (2013). The many faces of HMGB1: molecular structure-functional activity in inflammation, apoptosis, and chemotaxis. Journal of Leukocyte Biology, 93(6), 865-873. doi:10.1189/jlb.1212662

Yang, H., Lundback, P., Ottosson, L., Erlandsson-Harris, H., Venereau, E., Bianchi, M. E., . . Antoine, D. J. (2012). Redox Modification of Cysteine Residues Regulates the Cytokine Activity of High Mobility Group Box-1 (HMGB1). Molecular Medicine, 18(2), 250-259. doi:10.2119/molmed.2011.00389

Zhang, J., Takahashi, H. K., Liu, K., Wake, H., Liu, R., Maruo, T., . . Nishibori, M. (2011). Antihigh mobility group box-1 monoclonal antibody protects the blood-brain barrier from ischemia-induced disruption in rats. Stroke, 42(5), 1420-1428.

doi:10.1161/strokeaha.110.598334

Ziebell, J. M., Adelson, P. D., \& Lifshitz, J. (2015). Microglia: dismantling and rebuilding circuits after acute neurological injury. Metabolic Brain Disease, 30(2), 393-400. doi:10.1007/s11011-014-9539-y

This article is protected by copyright. All rights reserved. 


\section{Figure Legends}

Figure 1: Glial activation in adult and pediatric mouse brain. Representative images of Iba1 (a) and GFAP (b), indicating the morphology and distribution of microglia/macrophage and astrocyte reactivity, respectively. Examples from sham and TBI animals are shown, from tissue collected at $3 \mathrm{~d}$ post-TBI. Inserts illustrate immunopositive cells from TBI neocortex at higher magnification. CA1 = Cornu ammonis 1 (hippocampal proper region). DG = dentate gyrus of the hippocampus. Scale bar $=$ $100 \mu \mathrm{m}$.

\section{Figure 2: Glial activation differs across an acute time course after TBI in adult versus pediatric}

mice. ED1, a marker for activated microglia/macrophages, was significantly elevated at 3 and $7 \mathrm{~d}$ after TBI in the brains of adult mice (a; one-way ANOVA, post-hoc Tukey ${ }^{*} \mathrm{p}<0.05$ vs sham, ${ }^{* *} \mathrm{p}<0.05$ vs sham, $2 \mathrm{~h}, 6 \mathrm{~h}$ and $24 \mathrm{~h}$ ). In contrast, ED1 was elevated at $2 \mathrm{~h}$ after TBI in the brains of pediatric mice (c; \#p $<0.05$ compared to all other groups). GFAP, an astrocytic marker, was significantly elevated in at $3 \mathrm{~d}$ and $7 \mathrm{~d}$ post injury in the brains of adult mice (b; One-way ANOVA, post-hoc Tukey ${ }^{*} \mathrm{p}<0.05$ compared to $2 \mathrm{~h}$ and $24 \mathrm{~h},{ }^{* *} \mathrm{p}<0.05$ compared to $\left.24 \mathrm{~h}\right)$. This was also observed in the pediatric brain, but with an earlier elevation at $24 \mathrm{~h}$ post injury (d; \# $\mathrm{p}<0.05$ compared 
to sham, 2 h, 6 h and 24 h, \#\# p<0.05 compared to sham, 2 h, $3 \mathrm{~d}$ and $7 \mathrm{~d}$. ExampleWestern blots are shown for the target protein and loading control (GAPDH).

Figure 3: Tissue loss in the adult and pediatric brain after experimental TBI. Tissue sections from pediatric (a) and adult TBI animals (b) were stained with cresyl violet to visualize the extent of tissue loss at 3 d post-injury. Quantification of the intact cortical tissue both ipsilateral and contralateral to the injury site revealed significant tissue loss in both the pediatric (c) and adult (d) brain. There was no difference in percentage tissue loss from pediatric and adult mice (e). Unpaired ttests, ${ }^{*} \mathrm{p}<0.05,{ }^{* *} \mathrm{p}<0.005$. Scale $\mathrm{bar}=200 \mu \mathrm{m}, \mathrm{n}=6$ per group.

\section{Figure 4: HMGB1 immunofluorescence staining in pediatric brain after sham or TBI.}

Tissue sections from pediatric sham (a) and TBI mice (b, 3 days post-injury) were stained for HMGB1 and NeuN, a marker of mature neurons. Representative images were captured from various regions ipsilateral to the injury/sham procedure, for qualitative assessment of staining localization and distribution. Inserts illustrate immunopositive cells at higher magnification. Tissue from pediatric mice are presented, but similar findings were observed in the adult brain. CA1 $=$ Cornu ammonis 1 (hippocampal proper region). DG = dentate gyrus of the hippocampus. Scale bar $=100 \mu \mathrm{m}$.

Figure 5: Extracellular HMGB1 in adult and pediatric brain tissue. Tissue sections from pediatric and adult mice were stained for immunofluorescence of HMGB1, thresholded to a pre-determined amount for a mask, then all particles above $15 \mu \mathrm{m}$ were omitted to reveal non-cellular particles of HMGB1 (a). In the pediatric brain, there was an increase in both lesion core (b) and perilesional neocortex (c), as compared to sham. There was only an increase in the perilesional neocortex in adult 
mice (e), with no change in the lesion core (d) compared to sham. Unpaired t test, ${ }^{*} \mathrm{p}<0.05$ between groups, ${ }^{* *} \mathrm{p}<0.005$ between groups. Scale bar $=100 \mu \mathrm{m}, \mathrm{n}=6$ per group.

Figure 6: HMGB1 protein in total protein preparations and fractioned samples from adult and pediatric tissue. HMGB1 levels were quantified by Western blot in total protein samples (a, d), isolated cytosol $(\mathbf{b}, \mathbf{e})$ and isolated nuclear fractions $(\mathbf{c}, \mathbf{f})$ across a time course after TBI in both adult and pediatric mice. Increased levels of HMGB1 were observed at $3 \mathrm{~d}$ post-injury (a) but remained mostly stable across the time course in the fractioned tissue. In the pediatric brain, the HMGB1 levels remained stable in all fractions. One-way ANOVA, post-hoc Tukey, ${ }^{*} \mathrm{p}<0.05$ compared to sham and 7 d. Representative Western blots are shown for the target protein and loading control (GAPDH or Lamin B). n=7-8 per group.

Figure 7: HMGB1 in serum from adult and pediatric mice after experimental TBI. The concentration of HMGB1 changed across the time course in serum from pediatric TBI mice compared to sham controls (a). In contrast, HMGB1 levels in adult mice remained stable after TBI, consistent with sham controls (b). One-way ANOVA, post-hoc Bonferroni ${ }^{*} \mathrm{p}<0.05$ at $2 \mathrm{~h}$ compared to $7 \mathrm{~d}$.

This article is protected by copyright. All rights reserved. 


\section{University Library}

\section{- M M N E R VA A gateway to Melbourne's research publications}

Minerva Access is the Institutional Repository of The University of Melbourne

Author/s:

Webster, KM;Sun, M;Crack, PJ;O'Brien, TJ;Shultz, SR;Semple, BD

Title:

Age-dependent release of high-mobility group box protein-1 and cellular neuroinflammation after traumatic brain injury in mice

Date:

2019-04-15

Citation:

Webster, K. M., Sun, M., Crack, P. J., O'Brien, T. J., Shultz, S. R. \& Semple, B. D. (2019). Age-dependent release of high-mobility group box protein-1 and cellular neuroinflammation after traumatic brain injury in mice. JOURNAL OF COMPARATIVE NEUROLOGY, 527 (6), pp.1102-1117. https://doi.org/10.1002/cne.24589.

Persistent Link:

http://hdl.handle.net/11343/284828 